\title{
Removal of formation damage induced by drilling and completion fluids with combination of ultrasonic and chemical technology
}

\author{
Xian Shi ${ }^{a}$, Hongxing $\mathrm{Xu}{ }^{\text {b, }}{ }^{*}$, Liu Yang ${ }^{c, * *}$ \\ ${ }^{a}$ College of Petroleum Engineering, China University of Petroleum (Huadong), Qingdao, Shandong, 266555, China \\ b CCDC Changqing Down Hole Technology Company, Xi'an, Shanxi, 710000, China \\ ${ }^{c}$ Key Laboratory for Mechanics in Fluid Solid Coupling Systems, Institute of Mechanics, Chinese Academy of Sciences, Beijing, 100190, China
}

\section{A R T I C L E I N F O}

Article history:

Received 25 July 2016

Received in revised form 8 October 2016

Accepted 29 November 2016

Available online 7 December 2016

\section{Keywords:}

Formation damage

Drilling and completion fluids

Ultrasonic technology

Chemical remedy

Near-wellbore

\begin{abstract}
A B S T R A C T
Drilling fluids and completion fluids usually contains solids, high amounts of molecular and longchain polymers, which may result in severe permeability damage. The application of ultrasonic waves has been widely used for formation remedy but the effectiveness on polymer-induced damage is limited by downhole acoustic intensity. Thus, the combination of ultrasonic and chemical (acid and chlorine dioxide) technology has been experimentally investigated in this paper. The effect of core initial permeability and the ultrasonic irradiation characteristics, including frequency and time interval, on the cleaning results were then investigated by an ultrasonic technique such that the optimal ultrasonic parameters could be selected. Experimental results demonstrate that the ultrasonic energy and frequency have positive relationships with cleaning effectiveness, and treatment time duration was measured to extend beyond $60 \mathrm{~min}$ to ensure a sufficient physicochemical reaction. A comparison with the plugging removal effect with independent chlorine dioxide $\left(\mathrm{ClO}_{2}\right)$, acidizing, ultrasonic remedial treatments, and a combination of ultrasonic and chemical techniques indicates that the combination technique can produce better cleaning results because of the good coordination among the acid, oxidant and ultrasonic wave. The integration of acid, oxidant and ultrasonic technology is beneficial for long-chain polymer degradation and the removal of iron ion precipitation and solids, whereas ultrasonic energy can extend the chemical activation time3, increase the reaction rate and enhance the byproduct removal.
\end{abstract}

๑) 2016 Elsevier B.V. All rights reserved.

\section{Introduction}

Drilling and completion fluids, which are non-native fluids for contact with formation rocks, have the potential to invade the formation and react with formation minerals to cause formation damage. Both drilling fluids and completion fluids are composed of liquids, particles, and chemicals, so solid and polymer plugging of pores is the main formation damage mechanism. Damage induced by drilling and completion fluids exists in the majority of oil and gas wells and generally occurs at the first stage of well production, resulting in great reduction of the production rate (Longeron et al., 1995; Hands et al., 1998). Moreover, the usage volume of drilling

\footnotetext{
* Corresponding author.

** Corresponding author.

E-mail addresses: xuhongxing390124@163.com (H. Xu), shidayangliu@126.com (L. Yang).
}

and completion fluid is generally huge and is readily lost into the formation at overbalance drilling conditions, thus formation damage problems during drilling and completion stages are more serious than other types of formation damage such as organic depositions, including paraffin and wax. Therefore, it is meaningful to remove and mitigate the impact of formation damage due to drilling and completion fluids.

Remedial treatments for conventional formation damage include hydraulic fracturing and acidizing, but these technologies have some issues in fluid compatibility and HSE (health, safety and environmental). Therefore, the removal the formation damage or clean wellbore by ultrasonic technology was presented and has been widely developed in petroleum industry. Some literatures have already been reported on formation and wellbore stimulation by ultrasonic technologies. Some authors carried out experiments on the removal of asphaltene depositions, paraffin precipitation and wax about formation damage remediation with ultrasonic technology (Gollapudi et al., 1994; Zekri et al., 2007; 
Shedid, 2004; Brian et al., 2007). Recently, the laboratory study concerning the application of ultrasound to enhance well stimulation were discussed by some researchers (Bjorndalen and Islam, 2004; Amro et al., 2007; Tunio et al., 2011). The theory behind this was that when such a wave passes through porous media it will be dispersed into higher harmonics producing a series of effects that include: the disruption of the surface film, the coalescence of oil drops together with oscillation, and the excitation of oil drops trapped in capillaries (Mullakaevn et al., 2015). In addition, because fluid and rock interaction and high pressure at the wellhead can be avoided during ultrasonic stimulation treatment, thus it is regarded as one of the most promising techniques among wave methods for increasing well production rates. Comparing to the organic deposits, the main damage mechanism of drilling and complex fluids is more complex. Reed once summarized possible nine mechanisms of formation damage by drilling and completion fluids (Reed, 1989). Robert et al. presented the results of a wideranging investigation into the application of high-power sound waves to remove polymer induced damage from the wellbore and near-wellbore regions. But the removal effects were limited from their results (Roberts et al., 1993; Venkitaraman et al., 1995). Bahador performed a series of experiments about mud cake and mud filtration treatment with ultrasonic technology and there is an optimum ultrasonic radiation time for different ultrasonic wave intensities (Bahador, 2012). From the discussion above, tackling the formation damage issues by ultrasonic technology from both the drilling and completion fluids point of view was lacking. On the one hand, the damage mechanisms by drilling and completion fluids come from solids transport, local buildup of polymer concentration and filtrate invasion, ultrasonic technology alone was probably not effective at restoring permeability for this serious damage because ultrasonic effectiveness is limited by its power energy. On the other hand, the removal treatments of drilling and completion fluids by ultrasonic technology are generally performed repeatedly if removal effectiveness is limited, which means more cost and operation time. Thus, it's necessary to improve traditional ultrasonic technology in serious formation damage remedy.

In this paper, we follow up on work presented previously, in which the integration of ultrasonic and acidizing treatments was used simultaneously to reduce damage caused by drilling mud infiltration, fines migration and polymer concentration. In the first section, the main formation damage mechanisms due to drilling and completion fluids are discussed. In the next section, we discuss the experimental setups and experimental procedures taken throughout the investigation. Furthermore, to investigate the removal of damage effects by a combination of acoustic and some commonly used chemical treatments, acidizing (niobium hydroxide) and strong oxidants $\left(\mathrm{ClO}_{2}\right)$ were used in the experiments to accelerate the breakdown of high-chain polymer. The comparison of the measurement results for independent chemical damage removal, independent ultrasonic damage removal, and the combination of chemical and ultrasonic damage remove are given. Moreover, the influence of many relevant parameters of these new techniques are reported, and the study's conclusions are presented in the final section.

\section{Formation damage mechanisms and remedial treatments}

\subsection{Formation damage mechanisms}

A variety of fluids are used for drilling and completion engineering, thus mechanisms of formation damage by fluids are different. In general, two main reasons can be used to characterize the drilling fluids damaging mechanisms.

\section{(1) filtrate invasion}

The filtrate invasion of drilling and completion fluids to the formation usually happens when the wellbore pressure is greater than pore pressure. Drilling and completion fluids can induce clay minerals swell and the disintegrated solids results in a local buildup at pore throats, which cause permeability decline. Some authors think the clay expansion only have obvious effect on permeability damage if reservoirs contain as much as $5-10 \%$ smectite. In addition, when the expandable clays undergo expansion, this tends to destabilize the associated non-expanding clays and cause them to migrate and plug flow channels. Moreover, flowing non-nature liquids can invade into reservoirs and reduce flow capability of oil and gas or cause water blocking although water blocking can be avoided or alleviated to some degree by use of special drilling techniques, like underbalance drilling or the application of gasbased working fluids (Van der Bas et al., 2004).

\section{(2) solids and polymer plug}

Because the performance of drilling and completion fluids are influenced mainly by three main factors; i. e, fluid density, viscosity and $\mathrm{pH}$. Therefore, fluids usually consist many substances in solid phases, like drilled solids, weighting materials, and polymer, which can penetrate into formation and result in pore throats blocking (Poesio and Ooms, 2007). In addition, water-based drilling mud most commonly consists of Bentonite, with some additives such as Barium Sulfate (Barite), Calcium Carbonate (Calcite). Thus, drilling fluids mix underground fluids and rock, so if not compatible, precipitant from bacteria community or polymer can be generated. In particular, drilling fluid with more calcium chloride can cause formation damage when kill well for formation with connate water having bicarbonate. Precipitants due to drilling and completion fluids can block pore throats, which is more serious if mud cake is not created.

In addition to above formation mechanisms, the possible drilling and completion fluids induced formation damage mechanisms are summarized in Table 1.

\subsection{Formation damage remedial treatments}

Well productivity can be seriously reduced by formation damage formed by drilling and completion operations, thus numerous remedial treatments have been available to recover formation permeability after formation damage.

The conventional techniques to remove formation damage are mechanical treatments, acidizing stimulation and hydraulic fracturing, which get great success in some field applications. Several potential critical issues need to be considered before conventional permeability remedy. One is the compatibility between injected fluids and nature fluids. The second is the fluid placement efficiency, which probably divert and penetrate into unwanted flow channels. Thirdly, the remediation fluids, usually acids, used in matrix stimulation can cause apparatus and tubing corrosion, safety risk of toxic chemicals and environmental pollution. Mechanical methods only can utilize instruments like knives or hook et al. to remove deposits in the wellbore. Hydraulic fracturing is usually time consuming and expensive. Acidizing or is used as a remedial procedure, only if the hydraulic fracturing technologies are not feasible or successful. This technology involves the use of low and high concentration of acid that can redissolve and disperse the deposit, but it must be adapted in response to rock's mineralogy and physical properties. Because the application of some cross-linked polymer such as HPMC (hydroxypropyl methylcellulose) or PAM (polyacrylamide), 
Table 1

Formation damage types and mechanisms.

\begin{tabular}{|c|c|}
\hline Formation damage types & Formation damage mechanisms \\
\hline $\begin{array}{l}\text { capillary phenomenon } \\
\text { (1) relative permeability decrease } \\
\text { (2) wettability change } \\
\text { (3) water blocking }\end{array}$ & $\begin{array}{l}\text { (1) relative amounts of fluids change } \\
\text { (2) surfactant invasion } \\
\text { (3) viscous fluid invasion }\end{array}$ \\
\hline Pore throats clog & Solids invasion \\
\hline Scale & Inorganic precipitation \\
\hline $\begin{array}{l}\text { Rock damage } \\
\text { (1) Dispersed migration } \\
\text { (2) particles migration } \\
\text { (3) mineral precipitation } \\
\text { (4) lattice expansion } \\
\text { (5) not cemented }\end{array}$ & $\begin{array}{l}\text { (1) changes in the ionic environment } \\
\text { (2) dissolution of cement particles } \\
\text { (3) dissolution and minerals recrystallization } \\
\text { (4) too much water invades into crystal lattice } \\
\text { (5) the loose of formation structure }\end{array}$ \\
\hline
\end{tabular}

some oxidants (ammonium persulfate, bromate, enzyme et al.) were used to deal with damages from high molecular polymer or bacterium damage through oxidative degradation reactions. However, the temperature and pressure conditions limit oxidant wide application. They both have strict applicability conditions of a well, which can strongly influence the success of the treatment. Especially, they can be technically difficult to operate in multistage horizontal wells because of careful design on stages sequences and pumping schedule, which is especially true for matrix stimulation.

The use of ultrasonic to remove near-wellbore formation damage is a major shift from convention because it avoids the need for designer fluids and environmental friendly. The sound can pass through water or oil by vibration pattern, and ultrasonic waves sometimes can change the contact angle between fluid and the porous wall, thus oil droplets trapped inside pore spaces can be mobilized (Hamida and Babadagli, 2007; Kobayashi et al., 2000). Thus, this technology has been widely used in reduce formation damage from paraffin deposition, asphaltene precipitation, polymer or the other clogs that restrict oil flow in porous media. Compared with conventional stimulations, this cleanup technique has many advantages, such as effectively improving formation permeability, increasing reservoir fluids mobility, and relatively inexpensive. In addition, it complements existing stimulation technologies and enlarges range of options available for well stimulation. Instead of having to shut in the production, this technique can provide real-time stimulation services during production. Also, in a certain zone with heavy damage, this technique can be used repeatedly.

\section{Experimental study}

\subsection{Experimental apparatus}

An experimental setup has been designed to investigate the efficiency of the combination of ultrasonic cleaning and acidizing. The schematic of this experimental setup is shown in Fig. 1. The injection system includes a Teledyne ISCO pump, which injects the fluid across the core. The core holder is a standard Hassler sleeve core holder. It can hold cores of $2.54 \mathrm{~cm}$ in diameter with a length of $3-10 \mathrm{~cm}$. The radial confining pressure is supplied to the rubber sleeve surrounding the core by an automatic pressure tracking system, which has a pump controlled by a computer. Fluids can flow in either direction within the core by controlling the pipeline valves.

An ultrasonic transducer is mounted some distance away from one end of the core sample. To connect with the core holder, the transducer is specially designed. Six types of ultrasonic transducers are used in the experiments with ultrasonic frequency and rated power (Table 2). In addition, an oven, high-pressure vessels, vacuum pump, balance, and pure water machine are also used in the experiments. The core holder, high-pressure vessels and pipelines are placed in the oven to maintain a particular temperature when necessary. Fig. 2 shows ultrasonic transducers with different frequencies and power.

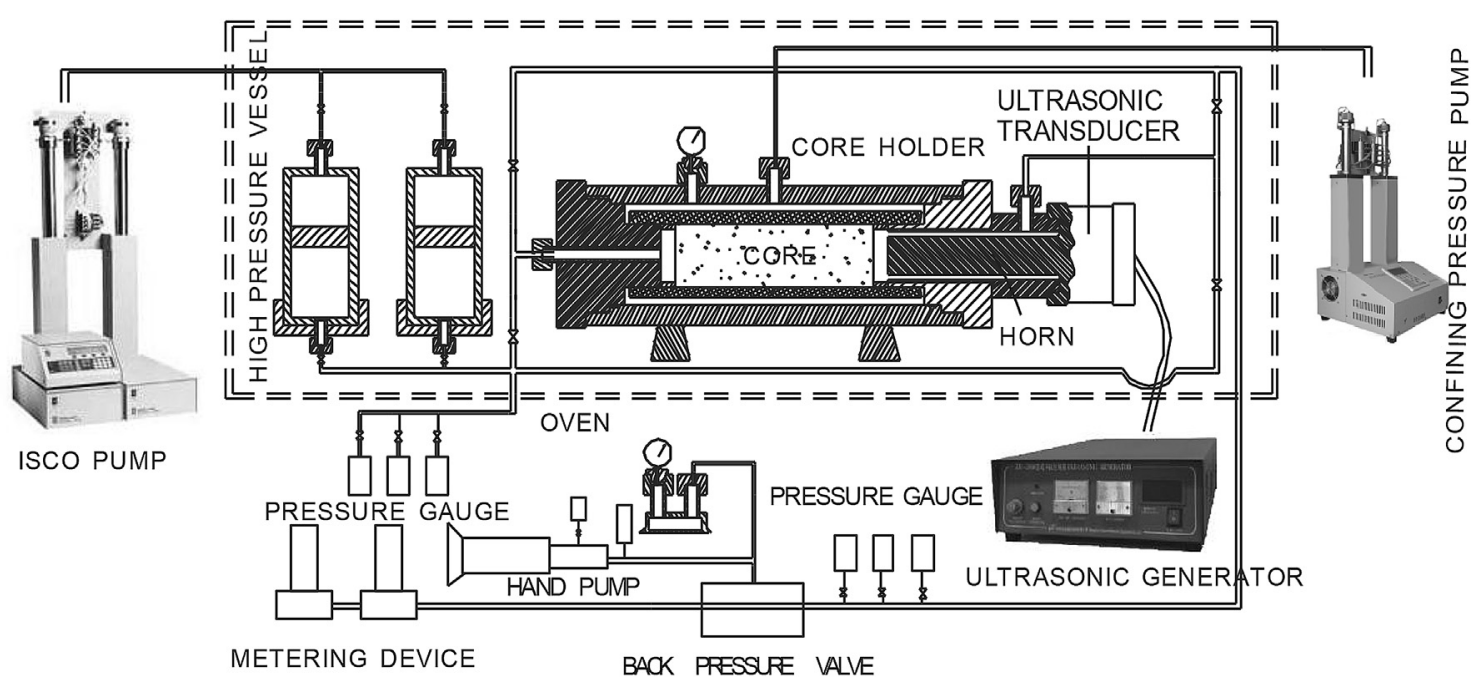

Fig. 1. Schematic of the experimental setup. 
Table 2

Ultrasonic parameters of transducer

\begin{tabular}{lll}
\hline Transducer No. & Transducer frequency & Transducer power ratings \\
\hline 1 & 18 & 1000 \\
2 & 22 & 1000 \\
3 & 25 & 1000 \\
4 & 30 & 60 \\
5 & 40 & 60 \\
6 & 50 & 200 \\
\hline
\end{tabular}

\subsection{Experimental materials}

The original cores used in the test have a diameter of $2.5 \mathrm{~cm}$ and a length of $7-8 \mathrm{~cm}$. These cores can be classified into three groups in accordance with their gas permeability (approximately $30 \mathrm{md}$, $80 \mathrm{md}$ and $150 \mathrm{md}$ ), with porosities between $18.9 \%$ and $21.9 \%$; the salinity of standard saltwater is $20,000 \mathrm{mg} / \mathrm{L}$ with formula of $\mathrm{NaCl}$ : $\mathrm{CaCl}_{2}: \mathrm{MgCl}_{2} \cdot 6 \mathrm{H}_{2} \mathrm{O}=7: 0.6: 0.4$. The best way to perform the laboratory experiments is to duplicate the actual borehole conditions as closely as possible. Thus, we use drilling fluids including low-solid water-based drilling and completion fluids from Shengli oilfields, China, to create artificially damaged cores. The drilling fluid consists of PHPA, bentonite clay, sulfonated filtrate reducer, sulfonated asphalt, bactericide, ultrafine calcium carbonate et al., and the completion fluid is composed of xanthan gum, hydroxyethyl cellulose, ultrafine calcium carbonate, dextrin et al. The other materials include $\mathrm{NaCl}, \mathrm{KCl}, \mathrm{MgCl}_{2}, \mathrm{Na}_{2} \mathrm{CO}_{3}$, and $\mathrm{CaCl}_{2}$, which are all analytical reagents. The acid used in this study is niobium hydroxide (wt.12\%HCL+3\% hydrogen fluoride), which is more suitable for mud and clay clog removal. The chlorine dioxide solution (wt. $0.5 \% \mathrm{ClO}_{2}$ ) was applied in the experiments. The aim of chlorine dioxide $\left(\mathrm{ClO}_{2}\right)$ is not only the removal of high-chain polymer and iron ion precipitation but also a bactericidal function. In the test, artificial cores were prepared and statured by saltwater, and then the initial liquid permeability of these was were determined. After that, the flow direction of the fluids in the cores is changed. Drilling fluid solution of $2 \mathrm{PV}$ is first injected, and then the displacement pump is stopped, and the outlet and inlet valves of the core holder are closed to maintain contact between the core and working fluids for $2 \mathrm{~h}$. In the next step, completion fluid solution of $2 \mathrm{PV}$ is injected, and the displacement pump is stopped for a $2 \mathrm{~h}$ waiting period. To ensure sufficient time for the reaction of solutions, the flow velocity should be controlled at $0.5 \mathrm{~mL} / \mathrm{min}$. Thus, drilling- and completion-fluid-induced plugs in cores were created, which include solid and polymer damage simultaneously.

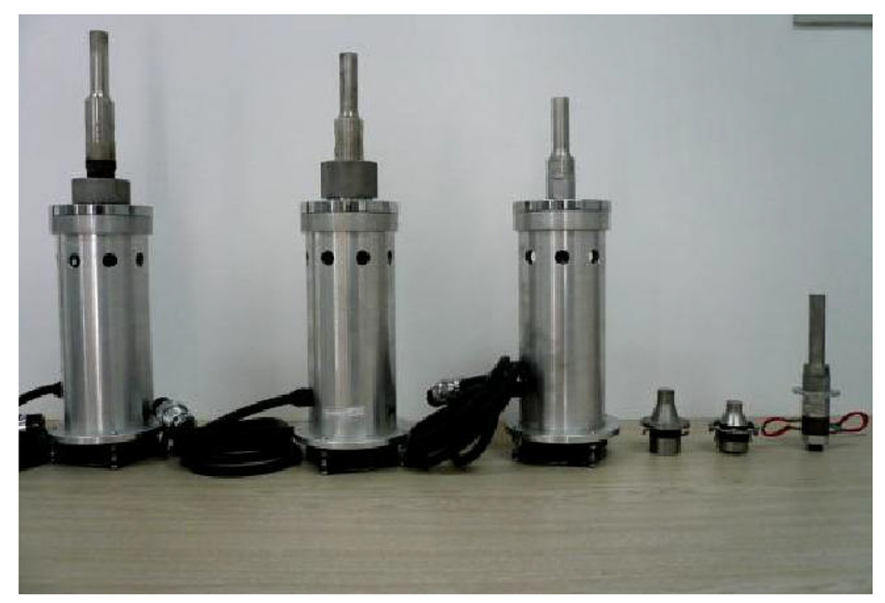

Fig. 2. Different ultrasonic transducers (left to right: No.1 to No.6).

\subsection{Experimental procedures}

The experiments were conducted under ambient laboratory temperature and atmospheric pressure conditions. The test procedure is given as follows: (1) Determine the basic parameters of the cores (gas permeability, porosity, etc.), and saturate it with standard brine before setting it in the core holder. Set the confining pressure, switch on the pump for waterflooding, and then determine the initial fluid permeability $\left(K_{i}\right)$ of the cores. (2) Generate the drilling-fluid-induced damage in the cores first, and follow the identical steps for completion fluids. (3) Change the flow direction of the fluids in the core again, and then start the pump for water flooding. Once the pressure difference between the two ends of the holder is stabilized, the permeability of the cores with the drillingfluid- and completion-fluid-induced damage $\left(K_{d}\right)$ should be determined. (4) Continue the water flooding operation. Use the No. 1 ultrasonic transducer to treat the core, with a 5 min break for every $10 \mathrm{~min}$. Stop when the total processing time by using ultrasound reaches $60 \mathrm{~min}$, and then determine the permeability of the cores after treatment by using the ultrasonic system $\left(K_{t}\right)$. (5) Repeat Steps (1)-(4), and use ultrasonic transducers No. 2-6 to process the core. The core permeability recovery $\left(\mathrm{PRR}=\left(K_{t}-K_{d}\right) / K_{i}\right)$ is taken as an index for evaluation of the plugging removal effects to determine the ultrasonic transducer with the best performance in removing formation damage. (6) Repeat Steps (1)-(3), and use the optimal ultrasonic transducer to treat the core. The total processing time is changed to determine the impacts of the total processing time of the ultrasonic system on the effect of plugging removal.

\section{Results and discussion}

In this study, the permeability recovery rate PRR is used to evaluate the extent of the restored permeability due to ultrasonic irradiation. Before starting the main experiments, some experiments were performed to select the optimal ultrasonic transducer. All removal tests were performed with processing time of at least 60 min by using the ultrasonic system. Following that, the effects of ultrasonic parameters including ultrasonic frequency, ultrasonic intensity and ultrasonic time internal on the core permeability recovery ability were compared.

It can be observed in Table 3 that the core permeability increases greatly after ultrasonic processing with transducers No.1, No.2 and No.3, which indicates the outstanding performance of the ultrasound in removing drilling-fluid- and completion-fluid-induced formation damage. The No. 2 ultrasonic transducer has the best plugging removal effects in cores with permeability of 30 md and 150 md, whereas the maximum damage degrees PRR of these two groups of cores are $27.5 \%$ and $21.5 \%$, respectively. In addition, the No. 3 ultrasonic transducer has the best plugging removal effects in the core with permeability of $80 \mathrm{md}$ and maximum damage degree PRR of approximately $24.23 \%$. However, ultrasonic energy does not always result in an evident increase in permeability for some cores if the ultrasonic frequency and power are not matched. The application of ultrasonic energy resulted in only a slight increase in permeability through transducers No.4, No.5 and No.6. However, owing to the complicated impacts of physical properties of cores and ultrasonic parameters, significant differences can be observed in the plugging removal effects of the ultrasonic system.

\subsection{Effects of processing time on permeability recovery}

Core samples suffering from drilling-fluid- and completionfluid-induced damage are exposed to different time intervals of ultrasonic irradiation of 20,40,60, 80, 100, 120, 140 and 160 min using the optimal transducer. The No. 2 ultrasonic transducer was 
Table 3

Experimental results of ultrasonic treatment for removal of drilling and completion fluids induced damage (60 min).

\begin{tabular}{|c|c|c|c|c|c|c|}
\hline Initial permeability (md) & Core no. & Transducer no. & $K_{i}(\mathrm{md})$ & $K_{d}(\mathrm{md})$ & $K_{t}(\mathrm{md})$ & $\left(K_{t}-K_{d}\right) / K_{i}(\%)$ \\
\hline \multirow[t]{6}{*}{30} & $3-1$ & 1 & 21.25 & 7.31 & 13.30 & 28.18 \\
\hline & $3-2$ & 2 & 21.84 & 8.09 & 14.38 & 28.79 \\
\hline & $3-3$ & 3 & 23.00 & 8.14 & 15.03 & 29.95 \\
\hline & $3-4$ & 4 & 21.46 & 8.32 & 9.93 & 7.53 \\
\hline & $3-5$ & 5 & 20.23 & 8.79 & 9.97 & 5.85 \\
\hline & $3-6$ & 6 & 19.87 & 7.88 & 9.73 & 9.29 \\
\hline \multirow[t]{6}{*}{80} & $4-1$ & 1 & 57.50 & 21.51 & 36.66 & 26.36 \\
\hline & $4-2$ & 2 & 63.20 & 21.83 & 38.82 & 26.89 \\
\hline & $4-3$ & 3 & 57.79 & 21.24 & 37.06 & 27.38 \\
\hline & $4-4$ & 4 & 63.57 & 22.85 & 27.51 & 7.33 \\
\hline & $4-5$ & 5 & 62.06 & 24.77 & 28.18 & 5.50 \\
\hline & $4-6$ & 6 & 57.75 & 23.91 & 29.34 & 9.40 \\
\hline \multirow[t]{6}{*}{150} & $5-1$ & 1 & 128.46 & 41.22 & 69.04 & 21.66 \\
\hline & $5-2$ & 2 & 113.97 & 45.40 & 72.53 & 23.80 \\
\hline & $5-3$ & 3 & 119.04 & 42.12 & 71.12 & 24.36 \\
\hline & $5-4$ & 4 & 102.43 & 40.05 & 46.32 & 6.12 \\
\hline & $5-5$ & 5 & 115.07 & 43.61 & 49.62 & 5.22 \\
\hline & $5-6$ & 6 & 114.79 & 43.39 & 54.02 & 9.26 \\
\hline
\end{tabular}

chosen to investigate the duration time on cores with $30 \mathrm{md}$ and $150 \mathrm{md}$, whereas the No. 3 ultrasonic transducer was selected to find the influence of ultrasonic treatment time on PRR for the artificial core with $80 \mathrm{md}$. All results are illustrated in Fig. 3 Basically, the results illustrate the increase in PRR with increasing applied ultrasonic irradiation time interval (UST). At the initial stage of ultrasonic treatment (0-60 min), almost all core permeability recovery rates were enhanced significantly; after the total processing time reaches $60 \mathrm{~min}$, the core permeability recovery rate stabilizes. The core permeability recovery rates reach the maximum value if the duration time is more than $80 \mathrm{~min}$; in other words, an optimal ultrasonic plugging removal effect is obtained at this treatment time. However, it can be observed that the core permeability recovery rates decrease with increasing duration time after the optimal treatment period.

Cavitation is regarded as the main stimulating mechanism in permeability recovery under atmospheric conditions. In general, cavitation can be defined as a special phenomenon of implosion of low-pressure microbubbles in fluids. Microbubbles of various sizes could induce strong oscillation, which can enhance fluid flow and mass transfer (Crum et al., 1999; Yusof et al., 2016). In formation damage recovery, the characteristics of acoustic cavitation are beneficial for long chains of polymer decomposition through stronger forces generated during cavitation. In addition, intensive cavitation phenomena can be generated between the transducer and the core, so the heat from ultrasonic sources can induce oxidation reaction to dissolve solids and reduce fluid rheology, which is helpful for polymer degeneration. However, the oxidation reaction is a dissipative and slow process, so a long processing time can lead to consumption of vast ultrasonic energy and consequently reduce the energy actually inflicted on the core. Moreover, the agitated waves generated by cavitation and the high pressure generated by bursting bubbles may produce back-pressure on the displacement facilities. Therefore, liquid flow within the core can be limited, especially for a relatively low-permeability core such as the artificial core with 30 md in this experiment. Thus, the processing time is not necessary too long according to different experimental conditions and economic consideration. There is an optimal combination of processing time, ultrasonic power and the other ultrasonic parameters. According to economical and application considerations, the optimal duration time by ultrasonic technology is approximately $60 \mathrm{~min}$ in this given case.

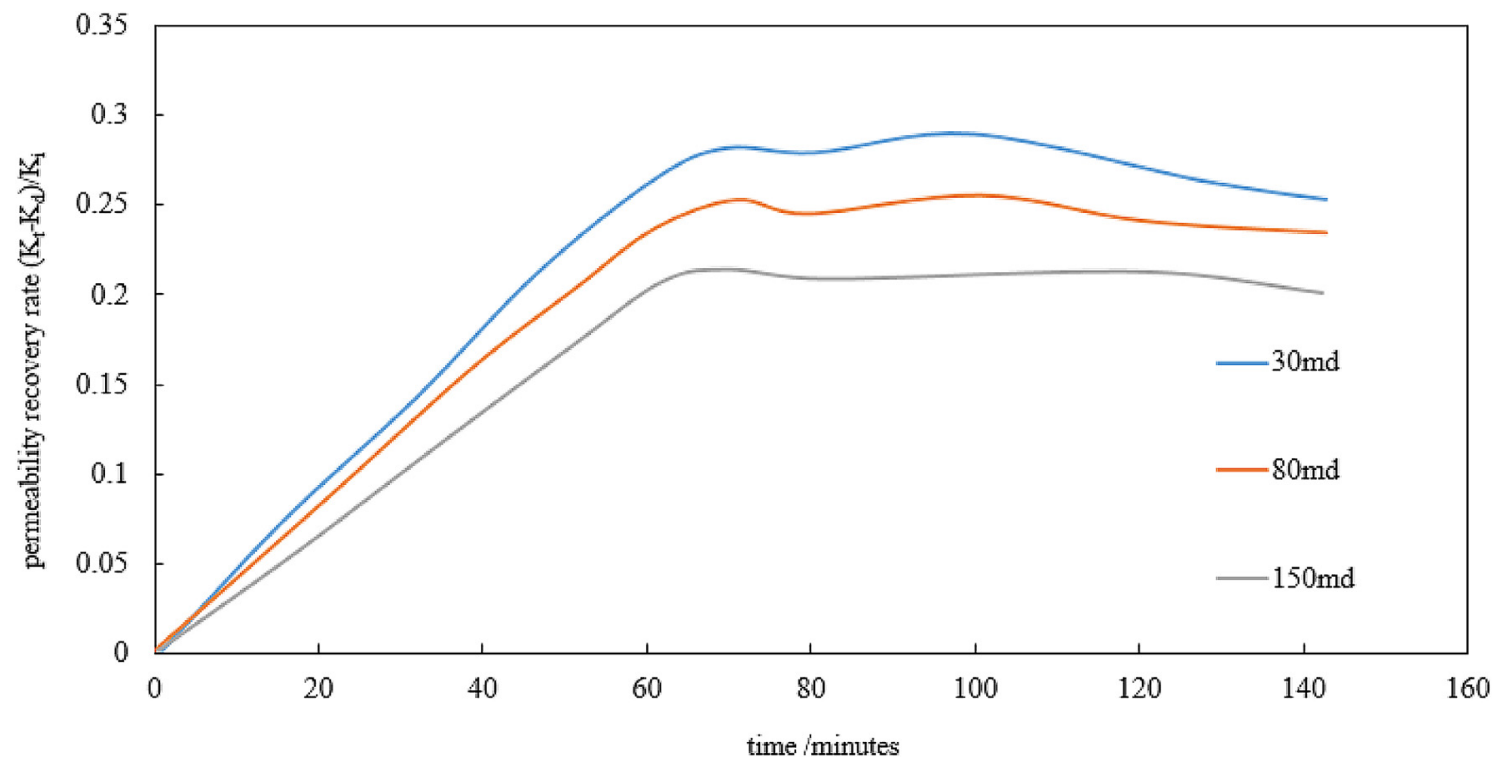

Fig. 3. Effect of treating time on permeability recovery of damaged cores. 


\subsection{Effects of ultrasonic power and ultrasonic frequency on permeability recovery}

The study of ultrasonic power on the permeability recovery rate can be investigated by the change of various transducers. From Fig. 4, it can be observed that transducers No. 1, No. 2 and No. 3 have much better permeability recovery effects than No. 4, No. 5 and No. 6 owing to the impacts of transducer power. Transducers No. 1, No. 2 and No. 3 each have $1000 \mathrm{~W}$ of nominal output power individually, transducers No. 4 and No. 5 each have $60 \mathrm{~W}$ of nominal output power, whereas transducer No. 6 has the lowest power output of $200 \mathrm{~W}$. The experimental result indicates that the permeability recovery rate effect is positively correlated with the energy intensities acting on the cores, which means that the native power of ultrasonic transducers controls the cleansing effectiveness to some extent.

To determine the impacts of ultrasonic frequency on permeability recovery, the results of the No. 1, No. 2 and No. 3 transducers were compared, and the results of the No. 4 and No. 5 transducers were compared, which have identical ultrasonic frequency. Compared with the PRR result of transducer No. 3, the PRR result obtained by the No. 2 transducer with lower ultrasonic frequency reveals better performance in terms of permeability recovery; the result of the comparison between the No. 4 and No. 5 transducers is similar. Thus, we can conclude that with decreasing ultrasonic frequency, higher ultrasonic frequency can produce better performance in most cases. However, the No.1 transducer has the lowest ultrasonic frequency but provides the lowest PRR. Although PRR increases with decreasing ultrasonic frequency, the change rate is limited. Thus, ultrasonic frequency has minor impacts on the PRR effect. According to classical vibrational energy theories, waves traveling in liquid media may experience attenuation (with consideration to sticking and thermal conducting effects of the liquid media). Higher frequency may lead to higher attenuation factor and consequently more severe ultrasonic energy losses. In this way, the actual energy on the core decreases. Moreover, some researchers persist with opposite opinions regarding the relationships between ultrasonic frequency and removal effects. These differences might originate from test conditions, plug types and the other factors. For instance, high power can increase the degree of fluctuation in temperature, thus asphaltene deposits turn to more difficult to remove. Moreover, the finer particles induced by ultrasound energy invade into the formation, creating additional damage rather than removal of the deposit. (Tutuncu and Robert, 2008). Therefore, the precise dynamic mechanisms responsible for the cleaning action are complex, and investigation is still ongoing. Therefore, it is necessary to select ultrasonic frequency according to specific conditions.

\subsection{Effect of initial permeability on permeability recovery}

Sonication was carried out at different power levels with the acoustic horn after damaging the core and backflowing it with brine. Comparing the cleaning results of the same transducer (Fig. 5), we find that the PRR of drilling-fluid- and completion-fluidinduced damage is related to the initial gas permeability of the cores. In particular, no increase in permeability was observed for cores with transducer No.4. Although the effect of initial permeability is insignificant, it can be observed that the lower initial gas permeability has greater PRR.

The basic damage mechanism for the drilling and completion is solid and polymer plugging. In particular, the polymer dominates as the critical permeability damage mechanism. In general, the larger pore spaces of cores have greater initial permeability, which means more chances for the reaction between liquid/liquid and liquid/ porous media. Thus, the use of different types of polymers in drilling and completion fluids are mixed, and molecules can aggregate to form a more stable structure, which increases the difficulty in removing the damage. Previous results also show that the net flow velocity generated by ultrasonic radiation decreases with increasing pore size, indicating that the increase in the initial permeability weakens the ultrasonic peristaltic transport and results in a reduced cleaning effect.

\subsection{Comparison of different remedial treatments}

The drilling and completion fluid damage experiments were initially conducted with dynamic flow equipment. The basic procedure consists of $60 \mathrm{~min}$ of acoustic cleaning, $60 \mathrm{~min}$ of acidizing, $60 \mathrm{~min}$ of acidizing and chlorine dioxide $\left(\mathrm{ClO}_{2}\right)$ oxidation cleaning, and $60 \mathrm{~min}$ of combination cleaning for damaged cores with different levels of permeability. In this section, the ultrasonic parameters were selected from the previous investigation and the duration time is $60 \mathrm{~min}$, and the No.2 transducer is selected in these experiments. Table 4 shows the comparison of the five types of damage remedies. The permeability of all damaged cores tends to

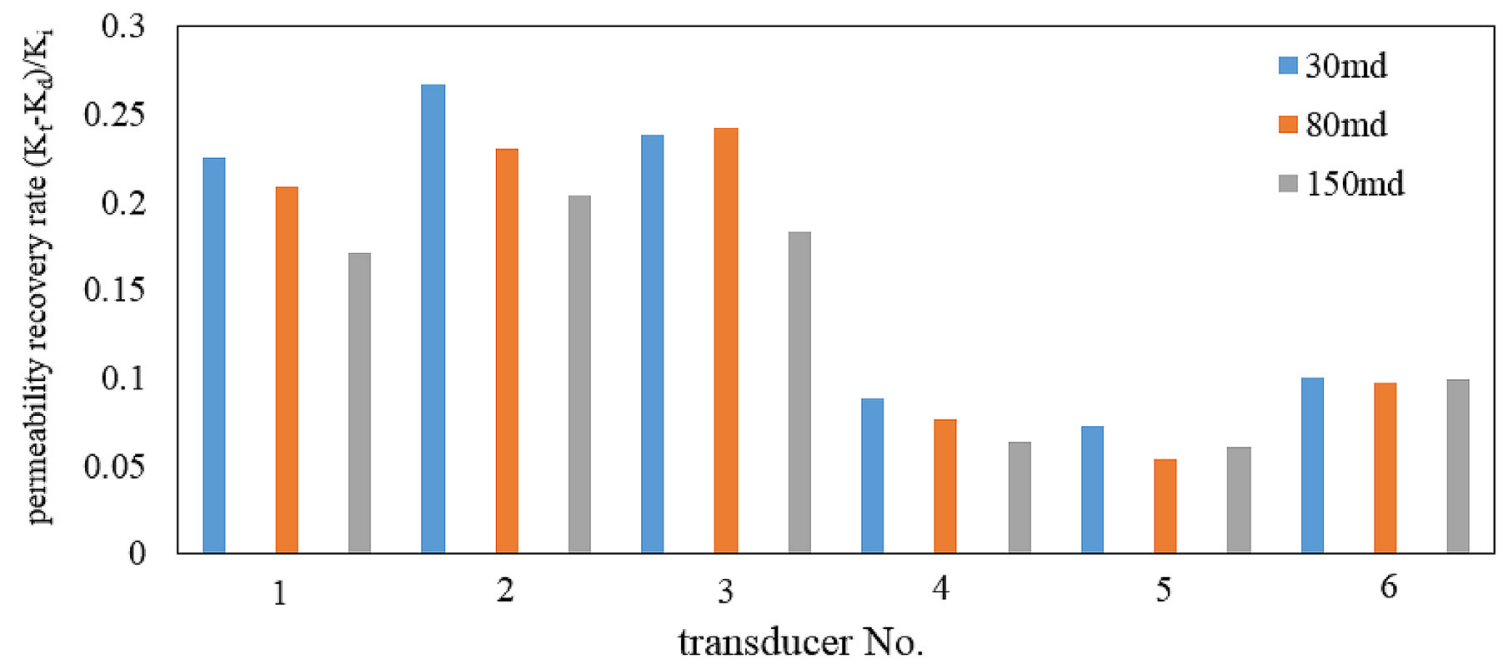

Fig. 4. Removal results by different ultrasonic transducers. 


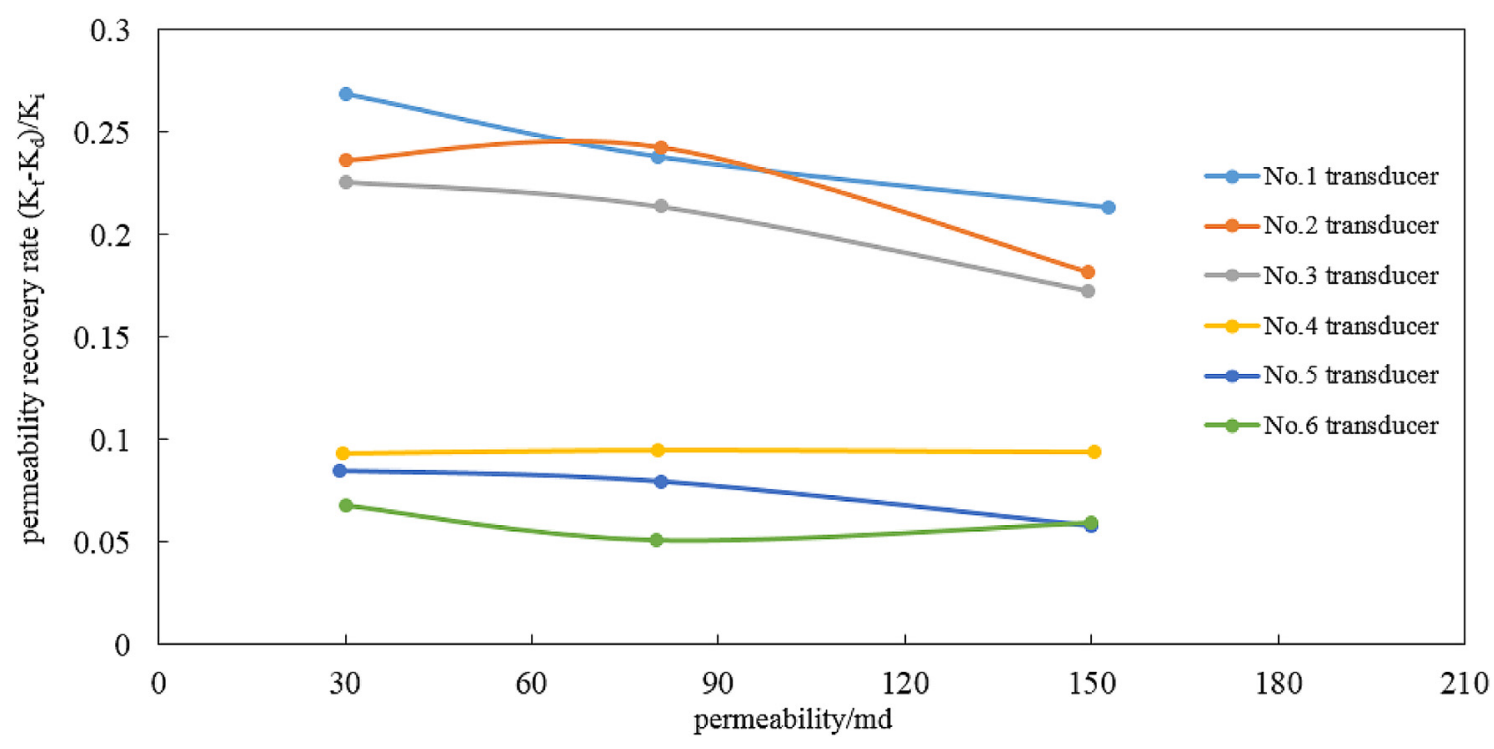

Fig. 5. Effect of initial permeability on the permeability recovery of damaged cores.

recover after ultrasonic cleaning. However, the effectiveness of an independent ultrasonic remedy on relatively low-permeability damaged cores is limited, which is similar to the effectiveness of conventional independent acidizing or independent strong oxidant treatment. However, the average permeability of the damaged cores significantly increased from approximately $20 \%-50 \%$ after combination treatments with ultrasonic technology. The comparison indicates that the combination of strong oxidant, acidizing and ultrasonic technology produce better performance compared with the other combinations of remedial treatments. In particular, the combination of ultrasonic radiation, oxidation and acidizing gives the best remedial effectiveness for cores with high permeability and the PPR approaches about 73.21\%.

\section{Discussion}

Mechanisms of a high-power ultrasonic system for permeability remedy include crushing of inorganic scales, ultrasonic cavitation effect, ultrasonic friction, and ultrasonic peristaltic transportation. At least two types of polymer (PHPA and xanthan gum) were added to the drilling and completion fluids, so the drilling- and completion-fluid-induced damage includes solids and polymer, which is much more difficult to remove acoustically than any other independent type of damage. Therefore, many problems of permeability damage factors require using a combination of two (or more) of remedial methods for getting the solution. The main damage mechanism is attributed to long chains of polymer and polymer induced precipitate. When drilling and completion fluids are injected into the core, polymer generates a bridging adsorption phenomenon in porous media owing to a combination of chain elongation and adsorption, which helps reduce the permeability of the core significantly. The adhesion force between the polymer and the pore wall is strong enough that ultrasonic microstreaming becomes less effective. The possible cleaning mechanism is ultrasonic cavitation, which could actually decompose the long molecular chains of polymer into a finer size. Consequently, the combination of ultrasonic technology and chemical treatment was necessary. Mixture with acidizing or chlorine dioxide $\left(\mathrm{ClO}_{2}\right)$ is beneficial for high-chain polymer degradation, whereas ultrasonic energy can extend the activation time and increase the reaction rate. Comparing to conventional ultrasonic technology, damaged cores significantly increased from approximately 20\%-50\% after

Table 4

The comparison of permeability recovery by acidizing alone and combination of acidizing and ultrasonic technology.

\begin{tabular}{|c|c|c|c|}
\hline Core No. & $K_{\mathrm{i}} / \mathrm{md}$ & Damage remedy & $\left(K_{\mathrm{t}}-K_{\mathrm{d}}\right) / K_{\mathrm{i}} / \%$ \\
\hline $3-7$ & 22.12 & Ultrasonic radiation with $60 \mathrm{~min}$ & 25.61 \\
\hline $3-8$ & 23.38 & Acidizing & 22.17 \\
\hline $3-9$ & 21.08 & Combination of Ultrasonic radiation and acidizing & 38.12 \\
\hline $4-7$ & 40.12 & Ultrasonic radiation with $60 \mathrm{~min}$ & 28.38 \\
\hline $4-8$ & 45.51 & Acidizing & 20.18 \\
\hline $4-9$ & 42.11 & Combination of Ultrasonic radiation and acidizing & 41.16 \\
\hline $5-7$ & 110.23 & Ultrasonic radiation with $60 \mathrm{~min}$ & 23.73 \\
\hline $5-8$ & 115.18 & Acidizing & 22.55 \\
\hline $5-9$ & 108.62 & Combination of Ultrasonic radiation and acidizing & 60.21 \\
\hline $6-7$ & 20.18 & Ultrasonic radiation with $60 \mathrm{~min}$ & 25.18 \\
\hline $6-8$ & 19.83 & oxidation and acidizing & 24.12 \\
\hline $6-9$ & 24.55 & Combination of Ultrasonic radiation, oxidation and acidizing & 49.89 \\
\hline $7-7$ & 43.12 & Ultrasonic radiation with $60 \mathrm{~min}$ & 26.64 \\
\hline $7-8$ & 46.82 & oxidation and acidizing & 27.36 \\
\hline $7-9$ & 44.15 & Combination of Ultrasonic radiation, oxidation and acidizing & 56.23 \\
\hline $8-7$ & 108.52 & Ultrasonic radiation with $60 \mathrm{~min}$ & 22.54 \\
\hline $8-8$ & 123.46 & oxidation and acidizing & 27.12 \\
\hline $8-9$ & 126.15 & Combination of Ultrasonic radiation, oxidation and acidizing & 73.24 \\
\hline
\end{tabular}


combination treatments and adoption of this technique is expected to be able to deliver improvements in more severe damage that occur in wells. Basically, there are two main reasons why ultrasonic energy is beneficial for activation time and reaction rate. Firstly, water can be decomposed into hydrogen ion $(\mathrm{H}+)$ and hydroxyl radicals ( $\mathrm{OH}-)$ in local high pressure and temperature induced by cavitation. Free active radicals have the strong capability of oxidation, which can enhance reaction rate. Secondly, ultrasonic act to break up the larger long chains of polymer structures, when bubbles collapse symmetrically due to cavitation, high intensity shock waves are generated. The higher of ultrasonic energy, the more bubbles collapse can occur. This has a positive impact on the decomposition of long chains of polymer to a finer size. Moreover, acid or chlorine dioxide $\left(\mathrm{ClO}_{2}\right)$ can flow into deep formations, which is helpful for deep formation damage remedy. In general, the significant challenge for conventional permeability recovery by acidizing or chlorine dioxide $\left(\mathrm{ClO}_{2}\right)$ is the possible depositions if acid or chlorine dioxide $\left(\mathrm{ClO}_{2}\right)$ is incompatible with rock minerals, but ultrasonic technology can generate mechanical forces, which improve the dissolution rate of the solids and depositions during the chemical reaction, so the incompatibility between unnatural chemicals and minerals can be mitigated.

\section{Conclusions}

Experiments were performed to investigate the effectiveness of using ultrasonic energy to reduce formation damage caused by drilling and completion fluids. In addition, the combination of ultrasonic and chemical technology was proposed to recover the permeability of artificial cores to the undamaged condition. Three conclusions can be drawn as follows:

(1) Removal of drilling-fluid- and completion-fluid-induced damage by ultrasonic technology is effective. The frequency, power density, duration of ultrasonic processing and initial permeability of cores have significant impacts on the performance of inorganic scale plugging removal by ultrasonic technology. Increased the recovered permeability with increasing ultrasonic power was found. In addition, lower ultrasonic frequencies can enhance the permeability recovery effects, but their impacts are limited. Ultrasonic treatment of 60 min can provide maximum permeability recovery for cores, so there is an optimal ultrasonic duration time.

(2) A previous study investigated the application of ultrasonic technology in mud cake removal and mud filtration treatment, but the study of polymers is rare. Because more than one type of polymer is probably included in drilling and completion fluids, the formation damage mechanisms include not only solid plugging but also polymer bridging. Therefore, the study of the combination of ultrasonic and chemical remedy technology is necessary. Independent acidizing, independent ultrasonic technology, the combination of ultrasonic technology and acidizing, and the combination of ultrasonic technology, strong oxidant and acidizing were compared experimentally under fair conditions. The comparison indicates that the combination of acidizing, strong oxidant and ultrasonic technology produces the best performance compared to the other types of combination technology.

(3) The results indicate that heat and oscillation generated by independent cavitation, oxidation or acidizing can cause polymer breakdown to some extent, but the effectiveness is still very limited. It was found that the average permeability of damaged cores increased by two times compared with each independent treatment because the integration of acid, oxidant and ultrasonic technology is beneficial for long-chain polymer degradation, removal of iron ion precipitation and solids, whereas ultrasonic energy can extend the chemical activation time, increase the reaction rate and enhance the byproduct removal, so the effectiveness of a combination of acidizing and ultrasound is the greatest.

\section{References}

Amro, M.M., Al-Mobarky, M.A., Al-Homadhi, E.S., 2007. Improved oil recovery by application of ultrasound waves to waterflooding. SPE paper 105370, SPE Middle East Oil and Gas Show and Conference, Manama, Bahrain, March 11-14.

Bahador V. 2012. Experimental investigation of formation damage reduction: mud cake removal and mud filtration treatment using ultrasonic wave radiation. SPE paper 160918.SPE Annual Technical Conference and Exhibition, San Antonio, Texas, October 8-10.

Bjorndalen, N., Islam, M.R., 2004. The effect of microwave and ultrasonic irradiation on crude oil during production with a horizontal well. J. Petroleum Sci. Eng. 43, 139-150.

Brian, T.F., Chejara, A.K., Saeid M. 2007. Experimental investigations of ultrasonic waves effects on wax deposition during crude oil production. SPE Paper109505. SPE Annual Technical Conference and Exhibition, Anaheim, California, November11-14

Crum, L.A., Mason, T.J., Reisse, J.L., Suslick, K.S., 1999. Sonochemistry and Sonoluminescence, NATO ASI Series C, vol. 524. Kluwer Publishers, London.

Gollapudi, U.K., Ban S.S., Islam M.R. 1994. Ultrasonic treatment for removal of asphaltene deposits during petroleum production. SPE Paper 27377. SPE International Symposium on Formation Damage Control, Lafayette, Louisiana, February $7-10$.

Hamida, T., Babadagli, T., 2007. Fluid-fluid interaction during miscible and immiscible displacement under ultrasonic waves. Eur. Phys. J. 60, 447-462.

Hands, N., Kowbel, K., Maikranz, S., Nouris, R., 1998. Drilling-in fluid reduces formation damage, increases production rates. Oil Gas J. 96 (28), 68-69.

Kobayashi, T., Kobayashi, T., Fujii, N., 2000. Effect of ultrasound on enhanced permeability during membrane water treatment. Jpn. J. Appl. Phys. 39 2980-2981.

Longeron, D., Argillier, J-F., and Audibert, A. 1995. An integrated experimental approach for evaluating formation damage due to drilling and completion fluids. SPE Paper 30089. European Formation Damage Conference, Hague, Netherlands, May 15-16.

Mullakaevn, M.S., Abramov, V.O., Abramova, A.V., 2015. Development of ultrasonic equipment and technology for well stimulation and enhanced oil recovery. J. Petroleum Sci. Eng. 125, 201-208.

Poesio, P., Ooms, G., 2007. Removal of Particle Bridges from a porous material by ultrasonic irradiation. Transport in Porous Media 66, 235-257.

Reed. 1989. Formation damage prevention during drilling and completion. SPE Centennial Symposium at New Mexico Tech, Socorro, New Mexico, October 16-19.

Roberts, P.M., Venkitaraman A., Sharma, M.M. 1993. Ultrasonic removal of organic deposits and polymer-Induced formation damage. SPE paper 31129. SPE Formation Damage Control Symposium, Lafayette, Louisiana, February14-15.

Shedid, A.S., 2004. An ultrasonic irradiation technique for treatment of asphaltene deposition. J. Petroleum Sci. Eng. 42, 57-70.

Tunio, S.Q., Tunio, A.H., Ghirano, N.A., El Adawy, Z.M., 2011. Comparison of different enhanced oil recovery techniques for better oil productivity. Int. J. Appl. Sci. Technol. 1 (5), 143-153.

Tutuncu A. N., Robert J. An Experimental Study for Removal of Near-Wellbore Asphaltene Deposits Using Ultrasonics. 2008 SEG Annual Meeting, 9-14 November, Las Vegas, Nevada.

Van der Bas, F., De Rouffignac, E., Zuidewijk, P. ,van Batenburg, D. 2004. Acoustic stimulation to mitigate near-wellbore damage. SPE paper 90356. SPE Annual Technical Conference and Exhibition, Houston, Texas, September 26-29.

Venkitaraman, A., Roberts, P.M., Sharma, M.M., 1995. Ultrasonic removal of nearwellbore damage caused by fines and mud solids. SPE Drill. Complet. 10 (3) $192-197$.

Yusof, N.S.M., Babgi, B., Alghamdi, Y., Aksu, M., Madhavan, J., Ashokkumar, M., 2016. Physical and chemical effects of acoustic cavitation in selected ultrasonic cleaning applications. Ultrason. Sonochemistry 29, 568-576.

Zekri, A.Y., Shedid, S.A., Alkashef, H., 2007. A new technique for treatment of permeability damage due to asphaltene deposition using laser technology. J. Petroleum Sci. Eng. 59, 300-308. 